\author{
Marianna OLENETS ${ }^{1}$ \\ Jerzy Zbigniew PIOTROWSKI ${ }^{2}$ \\ Anatoliy STROY ${ }^{3}$
}

\title{
METODA OKREŚLENIA EMISYJNOŚCI NIEKTÓRYCH MATERIAŁÓW BUDOWLANYCH
}

\begin{abstract}
W artykule przedstawiono analizę dostępnych metodologii, służących do określenia emisyjności powierzchni materiałów w warunkach eksploatacyjnych i laboratoryjnych. Odnosząc się do nich krytycznie, zaproponowano prostą metodę określenia emisyjności niektórych materiałów budowlanych oraz przedstawiono algorytm określenia emisyjności termicznej wybranego materiału. Metoda polega na opracowaniu modelu konwekcyjnej i radiacyjnej wymiany ciepła, zachodzącej miedzy cylindrycznym źródłem ciepła a zamkniętą przestrzenią skrzynki badawczej (modelu pomieszczenia). W modelu o kształcie sześciościanu o wymiarach $1 \times 1 \times 1 \mathrm{~m}$, umieszczono wewnątrz źródło ciepła o znanym polu powierzchni i emisyjności. Do pomiaru temperatury i gęstości strumienia ciepła użyto termopar i czujników gęstości strumienia ciepła. Materiał budowlany o badanej zdolności emisyjnej (w tym wypadku wyprawę tynkarską) naniesiono na ścianki modelu pomieszczenia od wewnatrz. Na podstawie danych pomiarowych określono całkowity strumień ciepła, dopływający do ścianek modelu pomieszczenia od źródła ciepła oraz temperaturę poszczególnych powierzchni, źródła ciepła i powietrza wewnątrz skrzynki badawczej. Wartości temperatur pozwoliły określić konwekcyjny strumień ciepła na powierzchni ścianek modelu pomieszczenia i źródła ciepła. Radiacyjny strumień ciepła określono jako różnicę miedzy całkowitym i konwekcyjnym strumieniem ciepła. Wartość radiacyjnej składowej z kolei dała możliwość określenia zdolności emisyjnej badanego materiału, którym pokryto powierzchnię ścianek. Na podstawie wyprowadzonych zależności i przeprowadzonych pomiarów ostatecznie określono współczynnik emisyjność wewnętrznej wyprawy tynkarskiej o małej gęstości z dodatkiem aerogelu.
\end{abstract}

Słowa kluczowe: emisyjność, model pomieszczenia, wymiana ciepła, konwekcja, promieniowanie długofalowe, aerogel

\footnotetext{
1 Autor do korespondencji: dr inż. Marianna Olenets, Politechnika Świętokrzyska w Kielcach, al. Tysiąclecia Państwa Polskiego 7, 25-314 Kielce, tel.: +48 508691335, mari_olensa@mail.ru 2 prof. PŚk dr hab. inż. Jerzy Zbigniew Piotrowski, Politechnika Świętokrzyska w Kielcach, al. Tysiąclecia Państwa Polskiego 7, 25-314 Kielce, piotrowski@tu.kielce.pl

3 prof. dr hab. inż. Anatoliy Stroy, Politechnika Świętokrzyska w Kielcach, al. Tysiąclecia Państwa Polskiego 7, 25-314 Kielce, anatolii_stroi@mail.ru
} 


\section{Wprowadzenie}

\subsection{Sformułowanie zadania}

Opracowując recepturę lub modyfikując skład materiałów budowlanych czy technologii wytwarzania istotne jest wyznaczenie ich charakterystyk fizykalnych. Niełatwym zadaniem jest określenie emisyjności z powodu złożoności procesu wymiany ciepła przez promieniowanie. Na intensywność radiacyjnej wymiany ciepła między ciałem a środowiskiem otaczającym, oprócz różnicy temperatur, ma także wpływ emisyjność i współczynnik konfiguracji, tj. wzajemnego rozmieszczenia materiałów. Dodatkowo miedzy materiałami i otoczeniem zachodzi również wymiana ciepła przez konwekcję.

\subsection{Cel i przedmiot badania}

Do określenia emisyjności dość często używa się termometrów infraczerwonych (pirometrów)[1, 2]. Istotną wadą pirometrów jest niewystarczająca dokładność pomiaru temperatury. Oprócz tego, o dokładności pirometru decyduje promieniowanie optyczne i określenie emisyjności obiektu. Dlatego ten sprzęt używany jest w przypadkach, gdy nie wymagana jest szczególna dokładność pomiarów, a obiekty znajdują się w pewnych odległościach. Praktycznie większość badań wyznaczających emisyjność wewnętrznych materiałów wykończeniowych $[5,6]$ polega na tym, iż badany materiał nanoszony jest na powietrznię promiennika (źródła ciepła), umieszczonego w modelu pomieszczenia. W takim przypadku dość trudno określić radiacyjny strumień ciepła, dopływający od źródła ciepła, jako oddzielną składową całkowitego strumienia ciepła. Oprócz tego gęstość strumienia ciepła ścianki jest dużo mniejsza niż gęstość strumienia ciepła źródła ciepła. By wyeliminować te mankamenty mające wpływ na dokładność obliczeń przy wykonywaniu badań emisyjności materiałów, w laboratorium fizyki budowli Politechniki Świętokrzyskiej przeprowadzono eksperyment w modelu pomieszczenia (skrzynce badawczej), w którym na wewnętrznej powierzchni naniesiono warstwę badanej wyprawy tynkarskiej, a źródło ciepła umieszczono wewnątrz modelu. Wykorzystując model obliczeniowy i badawczy przeprowadzono pomiary i określono emisyjność wewnętrznej wyprawy tynkarskiej o bardzo małej gęstości z dodatkiem aerogelu. Powietrze stanowiło ok. $90 \%$ całkowitej masy materiału.

\section{Opis stanowiska badawczego i przebiegu eksperymentu}

\subsection{Opis układu badawczego i sprzętu pomiarowego}

Stanowisko badawcze i jego schemat pomiarowy przedstawiono na rys. 1. Model pomieszczenia wykonano w kształcie sześcianu $100 \times 100 \times 100 \mathrm{~cm}$. Zrezygnowano z kształtu kuli [3], dla której strumień ciepła od źródła ciepła jest 
równomiernie dystrybuowany na gładkiej wewnętrznej powierzchni. Jednak ułożenie masy tynkarskiej na formie kulistej jest trudne do wykonania. Ścianki modelu badawczego wykonano z płyt OSB, które od wewnątrz pokryto warstwą badanego materiału. Źródło ciepła generowała żarówka elektryczna o mocy 100W.

Układ badawczy wyposażony został w urządzenia pomiarowe. Dla ułatwienia obliczenia powierzchni i prowadzenia pomiarów temperatury źródło ciepła osłonięto cylindrem o wymiarach: średnica $d=0,16 \mathrm{~m}$, długość $l=0,16 \mathrm{~m}$, z polem powierzchni $F_{z c}=0,1095 \mathrm{~m}^{2}$. Do określenia całkowitego strumienia ciepła, odpływającego od źródła ciepła prowadzono odczyty $\mathrm{z}$ amperomierza i woltomierza. Ponadto wartość strumienia ciepła kontrolowano za pomocą mierników gęstości strumienia ciepła, umieszczonych na zewnętrznej powierzchni ścianek modelu pomieszczenia. Do pomiarów wartości temperatur wykorzystano czujniki temperaturowe. W trakcie eksperymentu rejestrowano temperaturę powierzchni źródła ciepła $T_{z c}$ (osłony źródła ciepła), powietrza wewnątrz modelu pomieszczenia $T_{p w s}$ i na wszystkich wewnętrznych powierzchniach ścianek (na powierzchni warstwy masy tynkarskiej) $T_{1-4, p o k, d o ́ t}$
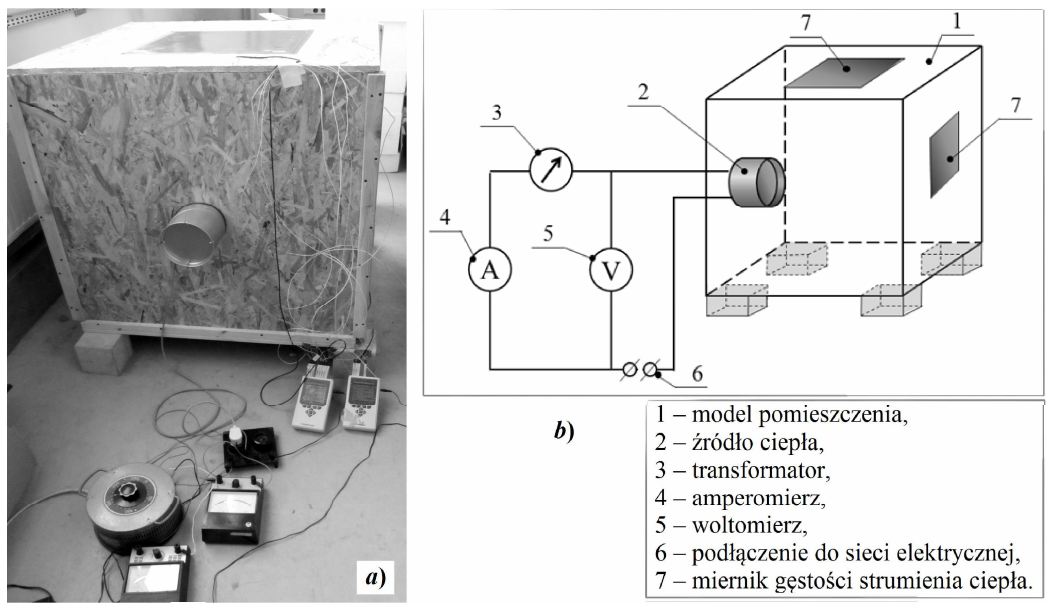

Rys. 1. Stanowisko badawcze (a) i schemat układu pomiarowego (b)

Fig. 1. General appearance $(a)$ and scheme of the experimental set-up (b)

\subsection{Metodologia przeprowadzenia badania}

Przy przeprowadzeniu badania eksperymentalnego, w celu ustalenia stanu bliskiego do stacjonarnego, badany układ podłączono do sieci elektrycznej $\mathrm{z}$ wyprzedzeniem kilkugodzinnym przed rejestracją parametrów obliczeniowych. 
Całkowity strumień ciepła dopływający do modelu pomieszczenia wynosi

$$
Q_{\Sigma}=I \cdot U
$$

gdzie: $I$ - natężenie prądu w sieci elektrycznej, A,

$U$ - napięcie elektryczne, $V$.

Uśrednioną gęstość strumienia ciepła przy powierzchni ścianek modelu pomieszczenia $q_{\Sigma}^{s c}$ i przy powierzchni źródła ciepła $q_{\sum}^{z c}$ określają wzory

$$
\begin{gathered}
q_{\Sigma}^{\text {sc }}=\frac{Q_{\Sigma}}{\mathrm{F}_{\mathrm{sc}}} \\
q_{\Sigma}^{\mathrm{zc}}=\frac{Q_{\Sigma}}{\mathrm{F}_{\mathrm{z} \mathrm{c}}}
\end{gathered}
$$

gdzie: $F_{z c}$ - pole powierzchni źródła ciepła (cylindra), $\mathrm{m}^{2}$,

$\mathrm{F}_{\mathrm{sc}}$ - pole wewnętrznej powierzchni ścianek modelu pomieszczenia, $\mathrm{m}^{2}$.

Całkowity strumień ciepła przy powierzchni źródła ciepła jak również przy powierzchni ścianek skrzynki badawczej jest sumą konwekcyjnego i radiacyjnego strumienia ciepła

$$
Q_{\Sigma}=Q_{r}+Q_{k}
$$

gdzie: $Q_{r}$ - radiacyjny strumień ciepła, W,

$Q_{k}$ - konwekcyjny strumień ciepła, W

$$
Q_{k}=\alpha\left(t_{\dot{z} c}-t_{p w s}\right) F_{\dot{z} c}
$$

gdzie: $t_{p w s}-$ temperatura powietrza w skrzynce badawczej, ${ }^{0} \mathrm{C}$,

$t_{z c}$ - temperatura powierzchni źródła ciepła, ${ }^{0} \mathrm{C}$,

$\alpha$ - współczynnik konwekcyjnej wymiany ciepła, $\mathrm{W} /\left(\mathrm{m}^{2} \cdot \mathrm{K}\right)$.

Równanie określające współczynnik konwekcyjnej wymiany ciepła ma postać

$$
\alpha=N u \lambda / h
$$

gdzie: $\lambda$ - współczynnik przewodzenia ciepła powietrza, $\mathrm{W} /(\mathrm{m} \cdot \mathrm{K})$,

$h$ - wymiar charakterystyczny, m,

$\mathrm{Nu}$ - liczba Nusselta 


$$
N u=C(G r P r)^{i}
$$

gdzie: $\mathrm{Gr}$ - liczba Grashofa,

Pr - liczba Prandtla.

Współczynnik $C$ i wykładnik $i$ dla różnych zakresów konwekcji zostały przedstawione w tabelach 1 i 2.

Tabela 1. Wartość wykładnika $i$ dla wzoru (7)

Table 1 . The value of the exponent $i$ for equation (7)

\begin{tabular}{|l|l|}
\hline dla $G r P r<1^{3}$ & $i<1 / 4$ \\
\hline dla $G r P r=1^{3}$ do $10^{9}$ & $i=1 / 4$ \\
\hline dla $G r P r>10^{9}$ & $i=1 / 3$ \\
\hline
\end{tabular}

Tabela 2. Wartość współczynnika $C$ dla wzoru (7)

Table 2. The value of the coefficient $C$ for equation (7)

\begin{tabular}{|l|c|c|c|c|c|}
\hline \multirow{2}{*}{ Układ } & \multicolumn{5}{|c|}{ Zakresy stosowności $\boldsymbol{C}$ dla wartości $\mathbf{G r P r}$} \\
\cline { 2 - 6 } & $\mathbf{d o \mathbf { 1 0 } ^ { 3 }}$ & $\mathbf{d o} \mathbf{1 0}^{\mathbf{9}}$ & $\boldsymbol{C}$ & powyżej 10 & $\boldsymbol{C}$ \\
\hline ściana pionowa, & $10^{4}$ & $10^{9}$ & 0,59 & $>10^{9}$ & 0,13 \\
cylinder pionowy & $5 \cdot 10^{2}$ & $2 \cdot 10^{7}$ & 0,54 & $>2 \cdot 10^{7}$ & \\
\hline rura pozioma, & $10^{3}$ & $10^{9}$ & 0,53 & $>10^{9}$ & \multirow{2}{*}{0,11} \\
drut & $10^{3}$ & $10^{9}$ & 0,47 & & \\
\hline płyta pozioma, oddająca ciepło w górę & $10^{5}$ & $2 \cdot 10^{7}$ & 0,54 & $>2 \cdot 10^{7}$ & 0,14 \\
\hline płyta, oddająca ciepło w dół & $10^{3}$ & $10^{9}$ & 0,35 & $>10^{9}$ & 0,08 \\
\hline
\end{tabular}

$$
G r=\frac{g \cdot \beta \Delta T \cdot h^{3} \cdot \rho^{2}}{\eta^{2}}
$$

gdzie: $g$ - przyspieszenie ziemskie $\mathrm{g}=9,81 \mathrm{~m} / \mathrm{s}^{2}$,

$\beta$ - współczynnik rozszerzalności objętościowej, $\beta=1 / 273,2+t_{w}, \mathrm{~K}^{-1}$,

$t_{w}$ - temperatura warstwy przyściennej, $t_{w}=t_{z c}+t_{p w s} / 2,{ }^{0} \mathrm{C}$,

$\Delta T$ - różnica temperatur między ścianą a powietrzem, ${ }^{0} \mathrm{C}$,

$\eta$ - lepkość dynamiczna, $\mathrm{kg} /(\mathrm{m} \cdot \mathrm{s})$,

$\rho-$ gęstość powietrza, $\mathrm{kg} / \mathrm{m}^{3}$.

Liczba Prandtla może być określona ze wzoru

$$
\operatorname{Pr}=\frac{v}{a}
$$

gdzie: $v$ - współczynnik lepkości kinematycznej, $\mathrm{m}^{2} / \mathrm{s}$,

$a-$ stała dyfuzji cieplnej, $\mathrm{m}^{2} / \mathrm{s}$.

Do obliczeń liczby Grashofa i Prandtla za pomocą równania (7) można określić liczbę Nusselta, a następnie - współczynnik konwekcyjnej wymiany ciepła $\mathrm{z}$ równania (6). 
Podstawowym warunkiem poprawności obliczeń konwekcyjnych strumieni ciepła przy powierzchni źródła ciepła i ścianek modelu pomieszczenia jest spełnienie równości

$$
Q_{k_{z} c}=Q_{k p o k}+Q_{k_{d o ́}}+Q_{k_{1}}+Q_{k_{2}}+Q_{k 3}+Q_{k 3},
$$

gdzie: $Q_{k \dot{z} c}-$ konwekcyjny strumień ciepła przy powierzchni źródła ciepła,W,

$Q_{k . p o k}, Q_{k . d o t}, Q_{k 1}, Q_{k 2}, Q_{k 3}, Q_{k 4}$ - konwekcyjny strumień ciepła przy odpowiedniej powierzchni wewnątrz modelu pomieszczenia, W.

Po uwzględnieniu równania (10), na podstawie równania (11) można określić uśredniony strumień ciepła przez promieniowanie

$$
Q_{r}=Q_{\Sigma}-Q_{k i c}
$$

Emisyjność powierzchni ścianek modelu można określić z zależności (12) na radiacyjny strumień ciepła od źródła ciepła do ścianek modelu

$$
Q_{r}^{1-2}=F \cdot \varepsilon_{z c} \cdot \mathcal{E}_{\dot{s} c} \cdot c\left(T_{\dot{z} c}^{4}-T_{\dot{s} c}^{4}\right) \cdot \varphi
$$

gdzie: $\mathrm{F}$ - obliczeniowe pole powierzchni, $\mathrm{m}^{2}$,

$\varepsilon_{s c}, \varepsilon_{z c}-$ emisyjność powierzchni ścianek modelu i źródła ciepła,

$\mathrm{c}$ - stała promieniowania ciała doskonale czarnego, $\mathrm{c}=5,67 \cdot 10^{-8}$ $\mathrm{W} /\left(\mathrm{m}^{2} \mathrm{~K}^{4}\right)$,

$T_{s c}, T_{z c}$ - temperatura powierzchni ściany i źródła ciepła, $\mathrm{K}$,

$\varphi$ - współczynnik konfiguracji, charakteryzujący część strumienia ciepła, padającego od źródła ciepła do ścianek modelu.

Jeśli powierzchnię $F_{\dot{s c}}$ przyjąć jako powierzchnie obliczeniową $F_{\dot{s c}}=F$, to strumień ciepła od źródła ciepła całkowicie dopływa do powierzchni ścianek modelu pomieszczenia i $\varphi=1,0$. Jeśli $F_{z c}=F$, to $\varphi$ jest równy $\varphi_{s c-z c}$, i określa się na podstawie związku, zwanego prawem wzajemności

$$
F_{z c} \cdot \varphi_{s c-i c}=F_{s c} \cdot \varphi_{i c-s c},
$$

a po przekształceniach

$$
\varphi_{\dot{s} c-\dot{z} c}=\varphi_{\dot{z} c-\dot{s} c} \frac{F_{\dot{s} c}}{F_{\dot{z} c}}
$$

Z równania (12) emisyjność materiału wyprawy wynosi 


$$
\varepsilon_{\dot{s} c}=\frac{Q_{r}^{1-2}}{\varepsilon_{\dot{z} c} \cdot F_{\dot{s} c} \cdot c\left(T_{\dot{z} c}{ }^{4}-T_{\dot{s} c}{ }^{4}\right) \cdot \varphi_{\dot{z} c-s c}} .
$$

\section{Analiza wyników badania emisyjności materiału budowlanego}

\subsection{Wyniki pomiarów}

Na stanowisku badawczym zostały przeprowadzone pomiary do określenia emisyjności tynku wewnętrznego $\mathrm{z}$ dodatkiem aerogelu. Wyniki pomiarów otrzymane w trakcie eksperymentu przedstawiono w tabeli 3 .

Tabela 3. Dane pomiarowe

Table 3. Measurement data

\begin{tabular}{|c|c|c|c|c|c|c|c|c|c|c|}
\hline \multirow[b]{2}{*}{ Czas } & \multirow{2}{*}{ 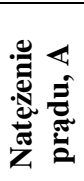 } & \multirow{2}{*}{ 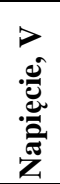 } & \multicolumn{2}{|c|}{ Średnia temperatura, ${ }^{0} \mathrm{C}$} & \multicolumn{6}{|c|}{$\begin{array}{l}\text { Średnia temperatura na wewnętrznej } \\
\text { powierzchni modelu pomieszczenia, }{ }^{0} \mathrm{C}\end{array}$} \\
\hline & & & $\begin{array}{c}\text { Źródła } \\
\text { ciepła } \mathbf{T}_{\mathrm{zc}}\end{array}$ & $\begin{array}{c}\text { Powietrza } w \\
\text { modelu pomiesz- } \\
\text { czenia } T_{\text {pws }}\end{array}$ & $\mathbf{T}_{\text {pok }}$ & $\mathbf{T}_{1}$ & $\mathbf{T}_{2}$ & $\mathbf{T}_{3}$ & $\mathbf{T}_{4}$ & $\mathbf{T}_{\text {dót }}$ \\
\hline 09:50 & \multirow{14}{*}{0,5} & \multirow{14}{*}{200} & 19,9 & 20,3 & 20,3 & 20,0 & 21,7 & 20,5 & 20,4 & 19,2 \\
\hline $10: 20$ & & & 40,7 & 23,3 & 25,3 & 22,1 & 23,8 & 22,4 & 22,3 & 20,5 \\
\hline 10:50 & & & 42,6 & 24,6 & 27,0 & 23,4 & 25,0 & 23,7 & 23,4 & 21,4 \\
\hline 11:20 & & & 43,3 & 25,3 & 27,9 & 24,1 & 25,3 & 24,3 & 23,9 & 22,0 \\
\hline 11:50 & & & 43,5 & 25,5 & 28,2 & 24,4 & 25,3 & 24,6 & 24,2 & 22,2 \\
\hline $12: 20$ & & & 42,4 & 26,0 & 28,8 & 24,8 & 26,0 & 25,0 & 24,8 & 22,6 \\
\hline $12: 50$ & & & 42,5 & 26,2 & 29,0 & 25,1 & 26,4 & 25,2 & 25,0 & 22,8 \\
\hline 13:20 & & & 42,4 & 26,3 & 29,0 & 25,1 & 26,0 & 25,4 & 25,0 & 23,0 \\
\hline $13: 50$ & & & 42,5 & 26,3 & 29,1 & 25,1 & 25,9 & 25,3 & 25,0 & 23,0 \\
\hline $14: 20$ & & & 42,5 & 26,2 & 29,0 & 25,1 & 25,8 & 25,4 & 25,0 & 23,0 \\
\hline $14: 50$ & & & 42,5 & 26,3 & 29,0 & 25,1 & 25,8 & 25,4 & 25,0 & 23,1 \\
\hline $15: 20$ & & & 42,5 & 26,2 & 29,0 & 25,1 & 25,7 & 25,4 & 25,0 & 23,1 \\
\hline $15: 50$ & & & 42,4 & 26,2 & 29,0 & 25,1 & 25,7 & 25,3 & 25,0 & 23,1 \\
\hline $16: 15$ & & & 42,6 & 26,2 & 29,1 & 25,1 & 25,7 & 25,4 & 25,0 & 23,1 \\
\hline
\end{tabular}

\subsection{Wyznaczenie emisyjności}

Całkowity strumień ciepła dla układu badawczego od źródła ciepła określono na podstawie wzoru (1) oraz pomiarów natężenia $I=0,5 \mathrm{~A}$ i napięcia elektrycznego $U=200 \mathrm{~V}$ (tabela 3 ). Moc strumienia ciepła od źródła ciepła wyniosła: 
$Q_{\Sigma}=I \cdot U=0,5 \cdot 200=100 \mathrm{~W}$

Gęstość strumienia ciepła przy powierzchni ścianek modelu $q_{\Sigma}^{s c}$ i przy powierzchni źródła ciepła $q_{\Sigma}^{z c}$ :

$$
\begin{aligned}
& q_{\Sigma}^{s c}=\frac{Q_{\Sigma}}{F_{\dot{s} c}}=\frac{100}{6}=16,7 \frac{\mathrm{W}}{\mathrm{m}^{2}} \\
& q_{\sum}^{z c}=\frac{Q_{\Sigma}}{F_{z c}}=\frac{100}{0,1095}=913 \frac{\mathrm{W}}{\mathrm{m}^{2}}
\end{aligned}
$$

Temperatura powietrza w skrzynce badawczej i na powierzchni źródła ciepła do obliczania zależności (5) wyniosły $t_{p w s}=26,3^{\circ} \mathrm{C}$ i $t_{z c}=42,5^{\circ} \mathrm{C}$.

Równanie współczynnika konwekcyjnej wymiany ciepła (6) obliczono w oparciu o temperaturę warstwy przyściennej

$t_{w}=t_{z c}+t_{p w s} / 2=42,5+26,3 / 2=34,4^{0} \mathrm{C}$,

oraz na podstawie tabeli 15.2 [4]:

$\lambda=0,0261 \mathrm{~W} / \mathrm{mK} ; \rho=1,112 \mathrm{~kg} / \mathrm{m}^{3} ; \eta=18,876 \cdot 10^{-6} \mathrm{~kg}(\mathrm{~m} \cdot \square) ; \operatorname{Pr}=0,71$, po okr $\_$sleniu współczynnika rozszerzalności objętościowej

$$
\beta=1 / 273,2+t_{w}=1 /(273,2+34,4)=0,00325
$$

oraz kryterialnej liczby Grashofa

$$
\begin{aligned}
& G r=\frac{g \cdot \beta \Delta T \cdot h^{3} \cdot \rho^{2}}{\eta^{2}}=\frac{9,81 \cdot 0,00325 \cdot(42,5-26,3) \cdot 0,16^{3} \cdot 1,112^{2}}{\left(18,876 \cdot 10^{-6}\right)^{2}}= \\
& =7,34 \cdot 10^{6}
\end{aligned}
$$

$$
G r \cdot \operatorname{Pr}=7,34 \cdot 10^{6} \cdot 0,71=5,21 \cdot 10^{6} .
$$

Z tabeli 1 i 2 wynika, że gdy $G r \cdot P r=5,21 \cdot 10^{6}<10^{9}$, wówczas $C=0,53, i=0,25$.

Po określeniu liczba Nusselta

$$
N u=C(G r P r)^{i}=0,53\left(5,21 \cdot 10^{6}\right)^{0,25}=25,32
$$

współczynnik konwekcyjnej wymiany ciepła wyniósł

$$
\alpha=N u \lambda / h=25,32 \cdot 0,0261 / 0,16=4,14 \frac{W}{m^{2} K}
$$


Po podstawieniu do wzoru (5):

$$
Q_{k}=\alpha\left(t_{\text {źc }}-t_{p w s}\right) F_{\text {żc }}=4,14(42,5-26,3) 0,1095=7,34 \mathrm{~W}
$$

ze wzoru (11) określono radiacyjny strumień ciepła, charakteryzujący ą wymianę ciepła w modelu

$$
Q_{r}=Q_{\Sigma}-Q_{k}=100-7,34=92,66 \mathrm{~W}
$$

Gęstość strumienia ciepła przy powierzchni ścianek modelu i przy powierzchni źródła ciepła

$$
q_{r}^{\dot{s} c}=\frac{Q_{r}}{F_{\dot{s} c}}=\frac{92,66}{6}=15,44 \frac{W}{m^{2}} \text { i } q_{r}^{\dot{z} c}=\frac{Q_{r}}{F_{\dot{z} c}}=\frac{92,66}{0,1095}=846,2 \frac{\mathrm{W}}{\mathrm{m}^{2}} .
$$

Przyjmując i wyliczając wartości do określenia radiacyjnego strumienia ciepła od źródła ciepła do ścianek modelu otrzymano $c=5,67 \mathrm{~W} / \mathrm{m}^{2} \mathrm{~K}^{4}, \varphi_{z c-s c}=1,0$. Na podstawie pomiarów temperatury źródła ciepła $T_{\dot{z}}=42,5^{\circ} \mathrm{C}$ i średniej temperatury ścianek $T_{s c}=25,6^{\circ} \mathrm{C}$ i odczytaniu emisyjności źródła ciepła z tabeli 15.8 [4] (ocynkowana blacha stalowa) emisyjność powierzchni badanej masy tynkarskiej z dodatkiem aerogelu z równania (14) wyniosła

$$
\mathcal{E}_{\dot{s c}}=\frac{92,66}{0,228 \cdot 6 \cdot 5,67 \cdot\left[(42,5+273)^{4}-(25,6+273)^{4}\right] \cdot 1,0}=0,64 \text {. }
$$

\section{Wnioski}

Sformułowano zależności do eksperymentalnego określenia emisyjności wybranego materiału budowlanego do wewnętrznych robót tynkarskich.

Przedstawiona metodologia powinna zostać zweryfikowana badaniami innych materiałów wykończeniowych.

Badania wspólfinansowane byly z Programu Operacyjnego Innowacyjna Gospodarka - projekt POIG.01.01.02-10-106/09-00 „Innowacyjne środki i efektywne metody poprawy bezpieczeństwa i trwatości obiektów budowlanych i infrastruktury transportowej w strategii zrównoważonego rozwoju”.

\section{Literatura}

[1] Holman J. P.: Experimental Methods for Engineers, Eight Edition, McGraw-Hill Companies, New York 2012. 
[2] IR Thermometers \& Pyrometers, Non-contact temperature measurement, Transactions in measurement and control, Section 3. vol. 1, 2nd edition, Putman Publishing Company and Omega Press LLC 1998.

http://www.omega.com/literature/transactions/volume1/thermometers1.html

[3] Judd Ross Leonard, Edited by Robert A. Granger.: Experiments in Heat Transfer and Thermodynamics, Chapter: experiment 23 - Determination of the emissivity of a heated cupper surface, Cambridge University, Press 1994, pp. 173-178.

[4] Kalinowski E.: Przekazywanie ciepła i wymienniki, Oficyna Wydawnicza Politechniki Wrocławskiej, Wrocław 1995.

[5] Kostowski Wojciech J.: Wyznaczenie emisyjności powierzchni ciał stałych, Instrukcja laboratoryjna, Laboratorium Techniki Cieplnej Politechniki Śląskiej http://www.itc.polsl.pl/newitc/files/studenci/laboratorium/techniki_cieplnej/instr_em isyjnosc.pdf.

[6] Panigrahi P. K., Nigam N.C.: Emessivity measurment, Heat and Mass Transfer, Experiment 2, India http://home.iitk.ac.in/ panig/ME341_EXP2.pdf.

\section{METHODOLOGY FOR DETERMINING EMISSIVITY OF SOME TYPES OF BUILDING MATERIALS}

\section{S u m m a r y}

The article presents an analysis of existing methodologies and apparatus for determination of materials emissivity under production and laboratory conditions. Their disadvantages were defined and a more simple method for the determination of the emissivity of some types of building materials was proposed. An algorithm of the emissivity determination of the chosen material was also presented. The article presents a method for determining emissivity of some types of building materials. The proposed method consists in developing of a model of convective and radiative heat transfer taking place between the cylindrical heat source and a square shell (model of the room). The model of the room is the cube of dimensions $1 \times 1 \times 1 \mathrm{~m}$, with the heat source arranged inside of it. The surface area and emissivity of the heat source are known. For temperature and heat flux measurement thermocouples and heat flux sensors were used. The building material with tested emissivity (e.g. plaster) is applied on the inner wall surface of the room model. Experimental measurement gives us the total heat flux, flowing to the walls of the room model from the heat source, the temperature of the walls surface in the room model and air temperature inside of it. Description of the method is illustrated by an example of emissivity determination for interior plaster with an extremely low-density which is kind of rigid foam with aerogel.

Keywords: emissivity, model of the room, heat transfer, convection, radiation, longwave radiation, aerogel

Przestano do redakcji: 22.11.2014 $r$.

Przyjęto do druku: 22.06.2015 r.

DOI:10.7862/rb.2015.64 